Article

\title{
The Role of Transdisciplinary Approach and Community Participation in Village Scale Groundwater Management: Insights from Gujarat and Rajasthan, India
}

\author{
Basant Maheshwari ${ }^{1, *}$, Maria Varua ${ }^{1}$, John Ward ${ }^{2}$, Roger Packham ${ }^{1}$, Pennan Chinnasamy ${ }^{3}$, \\ Yogita Dashora ${ }^{4}$, Seema Dave ${ }^{1}$, Prahlad Soni ${ }^{5}$, Peter Dillon ${ }^{2}$, Ramesh Purohit ${ }^{4}$, Hakimuddin ${ }^{5}$, \\ Tushaar Shah ${ }^{3}$, Sachin Oza ${ }^{6}$, Pradeep Singh ${ }^{4}$, Sanmugam Prathapar ${ }^{3}$, Ashish Patel ${ }^{6}$, \\ Yogesh Jadeja ${ }^{7}$, Brijen Thaker ${ }^{7}$, Rai Kookana ${ }^{2}$, Harsharn Grewal ${ }^{1}$, Kamal Yadav ${ }^{4}$, \\ Hemant Mittal ${ }^{4}$, Michael Chew ${ }^{1}$ and Pratap Rao ${ }^{4}$
}

1 School of Science \& Health, University of Western Sydney, Locked Bag 1797, Penrith NSW 2751, Australia; E-Mails: M.Varua@uws.edu.au (M.V.); r.packham@uws.edu.au (R.P.);

S.Dave@uws.edu.au (S.D.); H.Grewal@uws.edu.au (H.G.); entropygravity@gmail.com (M.C.)

2 CSIRO Land and Water Flagship, Glen Osmond, SA 5064, Australia;

E-Mails: John.ward@mekongfutures.com (J.W.); pdillon500@gmail.com (P.D.);

Rai.Kookana@csiro.au (R.K.)

3 International Water Management Institute, PO Box 2075, Colombo, Sri Lanka;

E-Mails: P.Chinnasamy@cgiar.org (P.C.); t.shah@cgiar.org (T.S.); S.Prathapar@cgiar.org (S.P.)

4 Department of Soil \& Water Conservation Engineering, Maharana Pratap University of Agriculture and Technology, Udaipur, Raj. 313001, India; E-Mails: yogita@gmail.com (Y.D.); purohitrc@yahoo.co.in (R.P.); pksingh35@yahoo.com (P.S.); kkyadavctae@gmail.com (K.Y.); hemant.mittal@rediffmail.com (H.M.); pratapsinghrao10@gmail.com (P.R.)

5 Vidya Bhawan Krishi Vigyan Kendra, Udaipur, Raj. 313001, India;

E-Mails: prahladsoni.baif@gmail.com (P.S.); hakimuddin_udr@yahoo.com (H.)

6 Development Support Centre, Ahmedabad, Guj. 380058, India;

E-Mails: sachin@dscindia.org (S.O.); ashishbmit@gmail.com (A.P.)

7 Arid Communities and Technologies, Bhuj, Guj. 370001, India;

E-Mails: yogeshjadeja@gmail.com (Y.J.); actkachchh@gmail.com (B.T.)

* Author to whom correspondence should be addressed; E-Mail: B.maheshwari@uws.edu.au;

Tel.: +61-2-4570-1235.

External Editor: Sharon Megdal

Received: 5 September 2014; in revised form: 3 November 2014 / Accepted: 5 November 2014 / Published: 11 November 2014 
Abstract: Sustainable use of groundwater is becoming critical in India and requires effective participation from local communities along with technical, social, economic, policy and political inputs. Access to groundwater for farming communities is also an emotional and complex issue as their livelihood and survival depends on it. In this article, we report on transdisciplinary approaches to understanding the issues, challenges and options for improving sustainability of groundwater use in States of Gujarat and Rajasthan, India. In this project, called Managed Aquifer Recharge through Village level Intervention (MARVI), the research is focused on developing a suitable participatory approach and methodology with associated tools that will assist in improving supply and demand management of groundwater. The study was conducted in the Meghraj watershed in Aravalli district, Gujarat, and the Dharta watershed in Udaipur district, Rajasthan, India. The study involved the collection of hydrologic, agronomic and socio-economic data and engagement of local village and school communities through their role in groundwater monitoring, field trials, photovoice activities and education campaigns. The study revealed that availability of relevant and reliable data related to the various aspects of groundwater and developing trust and support between local communities, NGOs and government agencies are the key to moving towards a dialogue to decide on what to do to achieve sustainable use of groundwater. The analysis of long-term water table data indicated considerable fluctuation in groundwater levels from year to year or a net lowering of the water table, but the levels tend to recover during wet years. This provides hope that by improving management of recharge structures and groundwater pumping, we can assist in stabilizing the local water table. Our interventions through Bhujal Jankaars (BJs), (a Hindi word meaning "groundwater informed" volunteers), schools, photovoice workshops and newsletters have resulted in dialogue within the communities about the seriousness of the groundwater issue and ways to explore options for situation improvement. The BJs are now trained to understand how local recharge and discharge patterns are influenced by local rainfall patterns and pumping patterns and they are now becoming local champions of groundwater and an important link between farmers and project team. This study has further strengthened the belief that traditional research approaches to improve the groundwater situation are unlikely to be suitable for complex groundwater issues in the study areas. The experience from the study indicates that a transdisciplinary approach is likely to be more effective in enabling farmers, other village community members and NGOs to work together with researchers and government agencies to understand the groundwater situation and design interventions that are holistic and have wider ownership. Also, such an approach is expected to deliver longer-term sustainability of groundwater at a regional level.

Keywords: managed aquifer recharge; groundwater monitoring; community engagement; sustainability; groundwater security 


\section{Introduction}

India is the largest user of groundwater in the world with an estimated usage of $230 \mathrm{~km}^{3}$ per year [1]. Globally, areas under groundwater irrigation are the highest in India (39 million ha), followed by China (19 million ha) and the USA (17 million ha), and at present $204 \mathrm{~km}^{3} \mathrm{y}^{-1}$ of groundwater is pumped annually in India [2]. Several reasons may be attributed to this phenomenon. Access to groundwater increased since the 1970s, when diesel and electric pumps became affordable to most small landholders. The causes of increased groundwater use are also rooted in population growth and economic expansion, and as result the annual groundwater use now probably exceeds the annual rainfall recharge. The notion of groundwater as a private resource, the rights of which are associated with land rights, has led to an exploitative extraction regime [3].

Farmers in semi-arid parts of India use groundwater to save rainfed crops from failure and to increase yields. As it is a relatively cheap and easily accessible water resource for individual farmers, irrespective of their farm size, groundwater is often extracted beyond its natural recharging capacity. With increased use of groundwater, the depth to the water table in many parts are fluctuating considerably during the year and the use of groundwater has risen to a level that groundwater from shallow aquifers is not adequate to meet the rising demand. Hence, groundwater from deeper aquifers is being pumped by the drilling of tube wells. There are also instances where fresh groundwater at shallow depths has been depleted, rendering marginal quality water from deeper layers of the aquifer [4]. The extensive use of groundwater resources by farmers all over the country pumping out water in an unregulated manner creates its own sets of complex management and sustainability issues.

The use of groundwater in agriculture is important in India, as it has enabled farmers to manage deficiencies in monsoonal rainfall, allowed dry-season irrigation, thus contributing to poverty alleviation. For this reason, a range of on-ground works to recharge groundwater are being implemented at the village scale throughout India as a part of the Government of India's "Mahatma Gandhi National Rural Employment Guarantee Act" (MNREGA) to enhance livelihood opportunities while developing a durable asset base. A significant part of the investment through MNREGA is for enhancing long-term, local water security by on-ground structures such as check dams, percolation tanks, surface spreading basins, pits and recharge shafts [5]. The development of on-ground structures to enhance groundwater recharge in India is called "watershed development". It is a long running program of Government of India and has significant hydrologic consequences, in particular, altering the runoff regime in downstream regions and groundwater recharge at local and regional scales.

In spite of all the efforts in the past to improve the sustainability groundwater in India, the problem of groundwater management is still severe, particularly in Rajasthan and Gujarat. In this project, called Managed Aquifer Recharge through Village level Intervention (MARVI), the research is focused on developing a suitable participatory approach and methodology with associated tools that will assist in improving supply and demand management of groundwater. Another important aspect of the project is education of and engagement with village communities, local NGO and government agencies to facilitate them working together to achieve sustainable groundwater management.

In this article, we report on some key findings from the MARVI project with two main objectives: (i) to show how basic hydrologic information collected by farmers and supplemented with hydrologic, agronomic and socio-economic data collected by the project team is leading to an assessment and 
understanding of the groundwater storage changes; and (ii) to reveal how this information and engagement activities can be used to empower village communities and other stakeholders to develop and assess their own viable options for groundwater management, including managed aquifer recharge and measures to reduce water demand while sustaining livelihoods.

\section{The Study Watersheds}

The work reported here was conducted in the Meghraj watershed in Aravalli district, Gujarat, and the Dharta watershed in Udaipur district, Rajasthan, India (Figure 1). Both watersheds have a semi-arid climate, with the average annual rainfall in excess of $600 \mathrm{~mm}$, but more than $90 \%$ of this rainfall is received during the monsoon months of June to September. Most farmers in the two watersheds grow maize, black gram, mungbean, guar, soybeans (recently introduced) and vegetables as Kharif crops during the rainy season. Wheat, gram and mustard are the main Rabi crops grown during the winter season. Farmers who have access to groundwater (and in some instances canal water) grow two crops a year and those who have access to water supplies throughout the year also grow some summer crops such as vegetables and fodder.

Figure 1. The Meghraj and Dharta watersheds. The inset map shows the location of the watersheds in the states of Gujarat and Rajasthan in India.

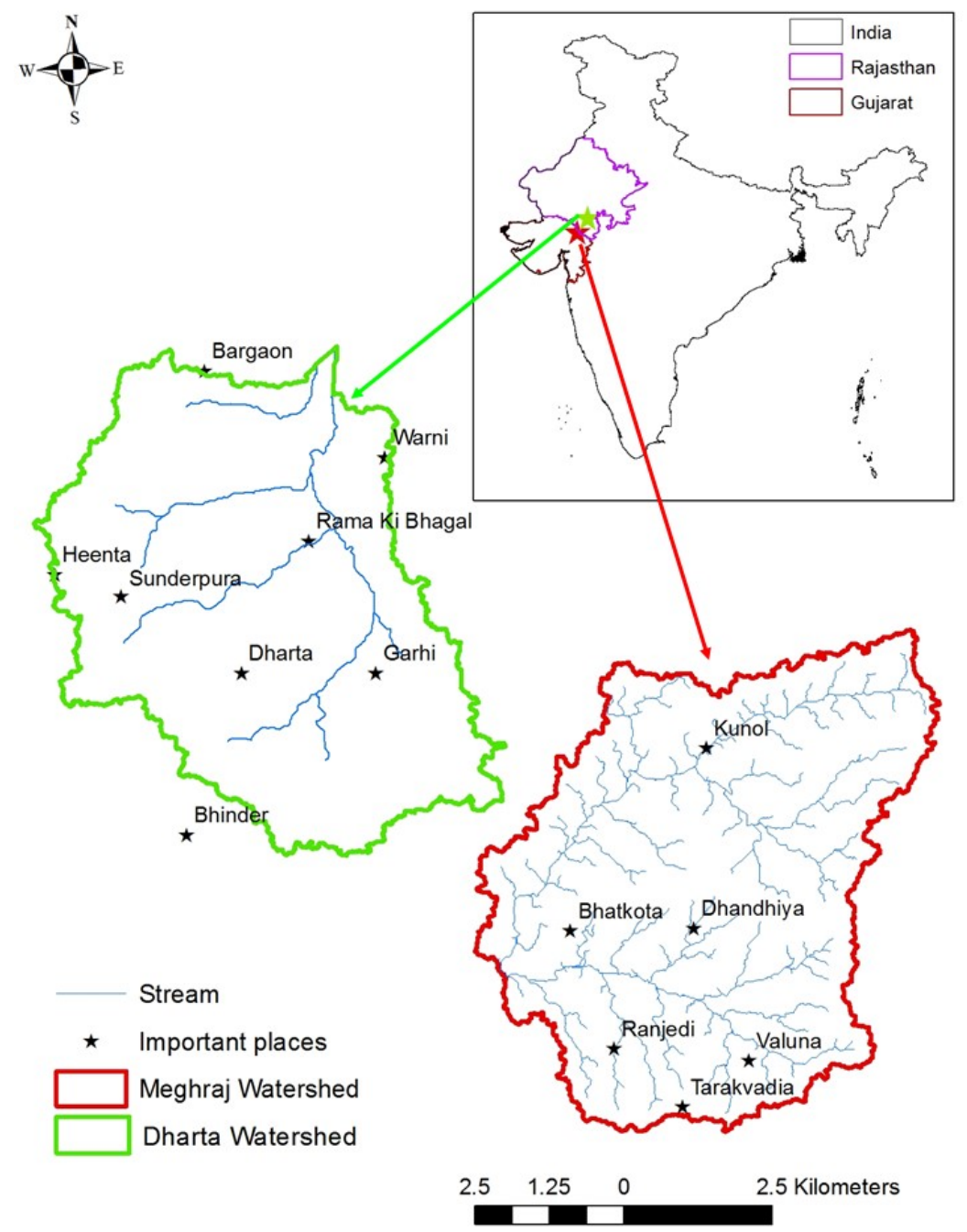


The occurrence and distribution of rainfall in both the Meghraj and Dharta watersheds are highly uneven in both time and space. Kharif crops are mainly dependent on the vagaries of the monsoon and are often at risk of either complete or partial crop failure due to inadequate rainfall, or rainfall not occurring at a critical stage of crop growth. Therefore, the uneven and erratic distribution of rainfall provides a major challenge to growing crops successfully and to sustaining a decent livelihood. When rainfall does not occur at the right time or in the required amount, some supplementary irrigation, also called "life saving irrigation", using rainwater stored on the surface or drawn from the underground aquifer systems can make a huge difference in avoiding crop failure.

A number of in situ conservation measures, including farm ponds, percolation ponds and check dams have been constructed in the two watersheds under both the Integrated Watershed Management (IWM) programs and MNREGA. The State Governments of Gujarat and Rajasthan, along with the Central Government have invested significant amounts in these two watersheds in the past, and continue to do so by constructing more of these structures. However, it is not clear how effective these programs are, and what impacts these investments are having on groundwater security. Figures 2 and 3 show the MAR structures in the Meghraj and Dharta watersheds.

Figure 2. Location of MARs in Meghraj.

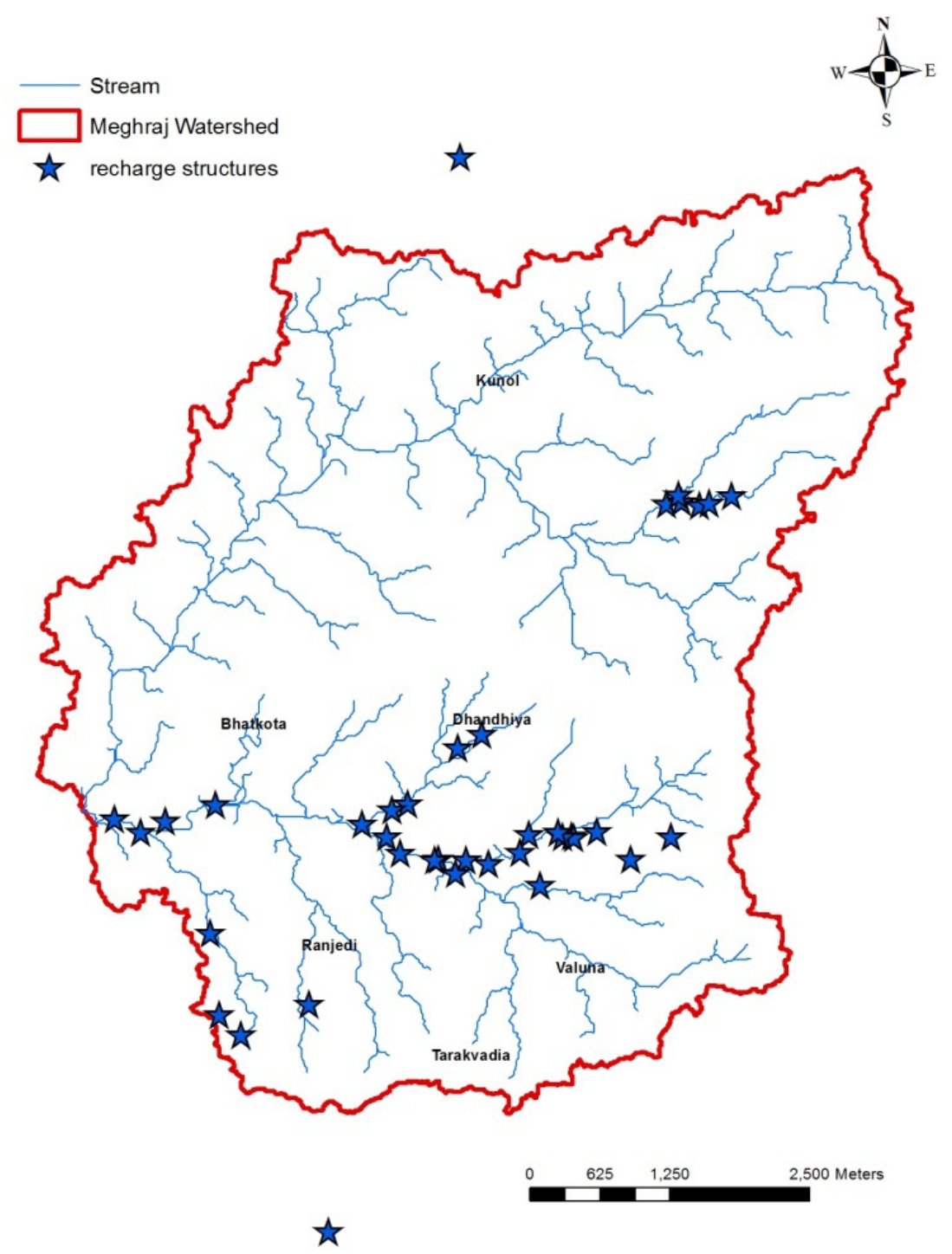


Figure 3. Location of MARs in the Dharta watershed.

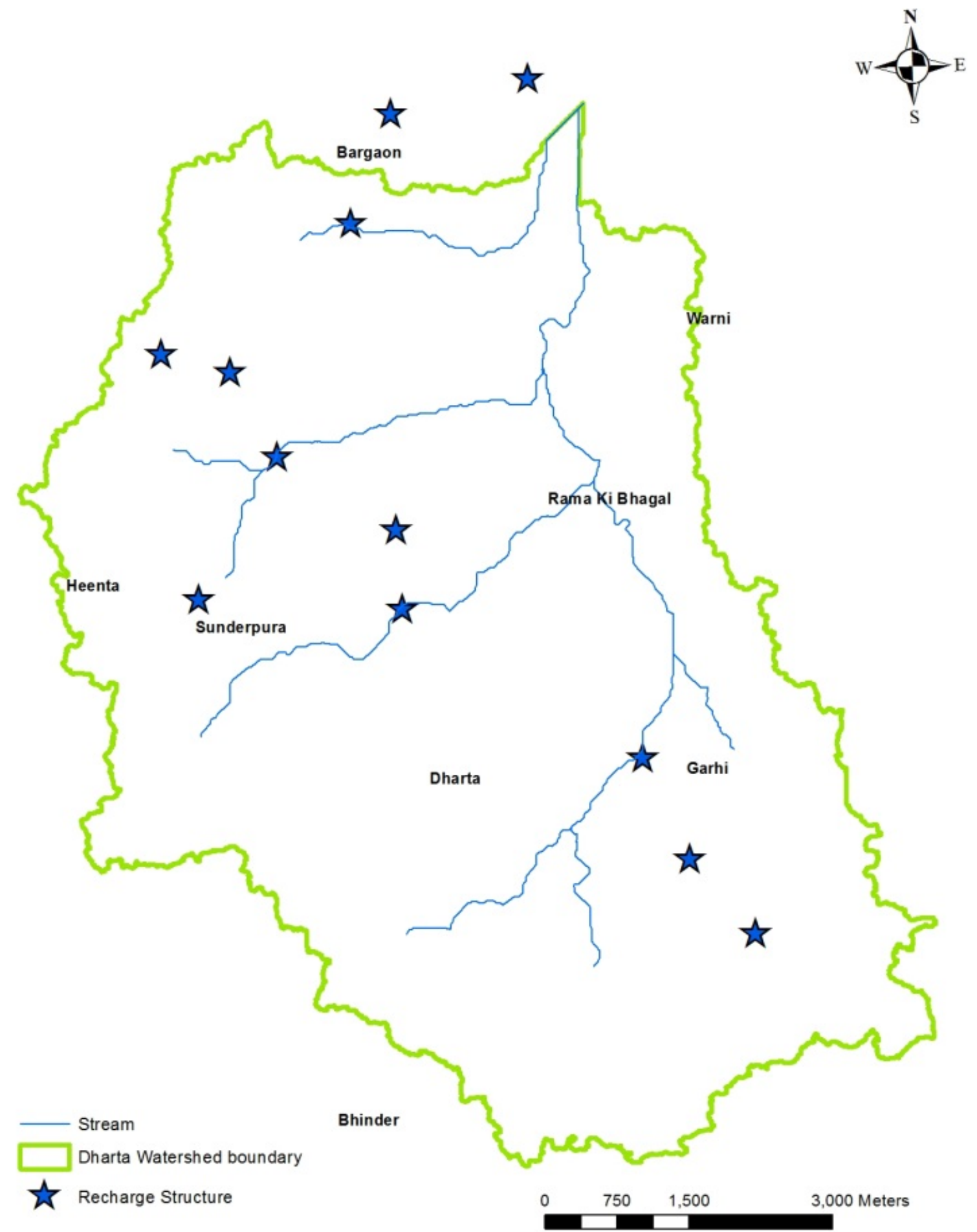

It is important to note that both watersheds are in hard rock aquifer areas. It well known that hard rock aquifers have low porosity and low connectivity and the movement of groundwater occurs through faults, fissures and fractures. Hence they store limited volumes, and when stored water is withdrawn by pumps, the emptied pores are not immediately filled by flows from adjacent areas. As result of low rain-recharge, and low porosity and low connectivity, the depth to water table fluctuates considerably during the year and significant water scarcity is often experienced during summer months or drier years. 
Most farmers in the Meghraj watershed belong to a tribal community, while those in the Dharta watershed are from mainstream groups. The farming practices in the two watersheds have not advanced adequately to cope with declining water supplies. For this reason, the physical and socio-economic conditions in the two watersheds provide a diversity of transdisciplinary research opportunities and engagement issues around groundwater recharge and management.

\section{Study Approach}

The study approach in the MARVI project is underpinned by transdisciplinary research with a main focus at the "village scale" to understand the complex interrelations between rainfall, aquifer recharge, groundwater pumping and livelihood opportunities. We define transdisciplinary research as one in which both researchers from different unrelated disciplines and non-academic participants, such as farmers and other villagers, work together for a common goal and create new knowledge and theory to improve a complex situation. Thus, in this project we recognized the importance of involving local villagers and other stakeholders through this approach during the research process and engaged them in participatory groundwater monitoring and education to explore options for groundwater sustainability. Figure 4 illustrates the application of relevant social and natural sciences research and engagement to improve the field situation.

Figure 4. Study approach in MARVI project.

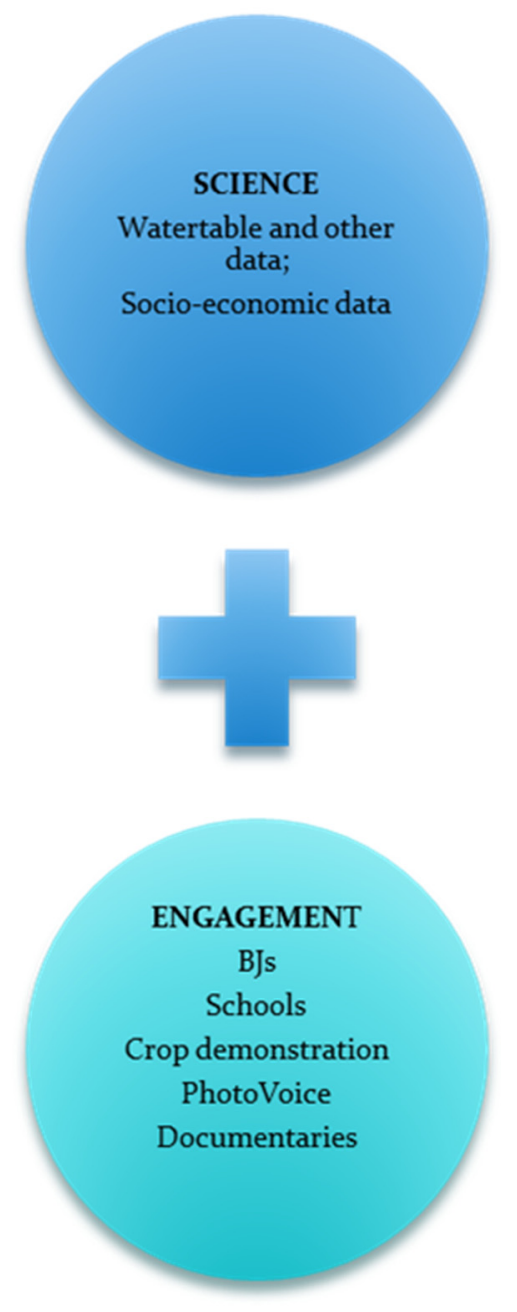

\section{SITUATION IMPROVEMENT}

- Understand what has been happening to groundwater and livelihoods

-Awaken community about their situation -Facilitate farmers to think differently about their groundwater futures and let them come up with ideas for situation improvement

-Engage with government agencies and help them to use project outputs for more effective groundwater management 
With an active engagement of local villagers, the project team collected a range of hydrologic, agronomic, economic, social and cultural data at selected clusters of villages over a two-year period. The engagement of villagers and data collected are then employed to understand the current situation and develop bio-physical and socio-economic insights to evaluate the current issues, identify options and strategies, provides a scientific and evidence-based input to enhance watershed development policies.

\section{Field Research and Data Analysis}

\subsection{Participatory Groundwater Monitoring}

A desired outcome of the MARVI project would be collective action at village level that is mutually beneficial to all the villagers, and from which other communities could learn. To achieve this, [6] have shown the need to develop Social Capital. This project used participatory approaches to help to develop social capital competences, with training programs aimed at supporting cognitive aspects of this social capital competence. In addition, the project used participatory monitoring for some data collection to also support this development.

Participatory monitoring of the water table was achieved through the engagement of villagers in the two watersheds. A total of nine local villagers, called Bhujal Jankaars (BJs)-a Hindi word meaning "Groundwater Informed" volunteers - were recruited in the Meghraj watershed and similarly 25 BJs were selected in the Dharta watershed. The main idea of recruiting BJs into this project was to give local villagers ownership in the project, build their capacity so that they can understand their groundwater issues and eventually help them to become champions of their community for improving the groundwater situation. The BJs were trained in a number of relevant aspects, such as mapping, water table and water quality measurements. They were also exposed to basic hydro-geologic concepts influencing groundwater availability for agricultural use.

The BJs were involved in weekly monitoring of the water table in open wells, 110 wells in the Meghraj watershed and 250 in the Dharta watershed. Prior to the monitoring of wells, all BJ's did a baseline survey with the help of the project team to compile the required information about village wells. The BJs monitored the groundwater changes through the measurement of water level depth from the ground surface on weekly basis and pH and EC on monthly basis. To assist in the reliability of the data collected by BJs, the project staff each week randomly measured the water level depth data in some of the wells using the same method as those of the BJ and crosschecked water level depths with those measured by BJs. This ensured that BJs were collecting the data properly.

\subsection{Hydrologic Measurements}

Two automatic weather stations, one in each watershed, were installed to collect local weather information for water balance modeling and evaluating the effectiveness of recharge structures on groundwater levels. In addition, six automatic rain gauges were installed in local schools in the Meghraj watershed and five in the Dharta watershed. The purpose of engaging schools in rainfall measurements was to make the school children aware of the water availability in the area and its importance. Some villagers, acting as BJs in the two watersheds, were also given manual rain gauges to monitor rainfall. 
A total of five groundwater depth sensors were installed in the Dharta watershed and three in the Meghraj watershed for monitoring water table depth at $15 \mathrm{~min}$ intervals. The measurement of water table depth at such a short interval is helpful to analyze rapid changes in water table depth following a pumping event or significant rainfall occurrence. Four water meters in each watershed were installed to measure pumped volume and water productivity for specific crops. Groundwater and soil samples were collected in the watersheds at different times during the study to examine whether they impose limitations for crop production and consequently on the livelihood of people.

The Central Ground Water Board (CGWB), an Indian Government organization, maintains and monitors observation wells across the country. In Gujarat and Rajasthan, CGWB monitors 1197 and 1111 wells, respectively [7]. The data is collected four times, Post-Monsoon (Rabi), Pre-Monsoon, Monsoon and Post-Monsoon (Kharif), which correspond to January, May, August and November respectively. For the current study, we chose two wells that fall in our study watershed areas. The data was collected from the WRIS website [8] which is maintained by the Indian Space Research Organisation (ISRO) and Central Water Commission (CWC).

\subsection{Socio-Economic Survey}

Households in the two watersheds that contributed to this study were identified through the first survey step - participatory community assessments. With the help of community leaders and extension workers, a total of 500 households from eleven villages from the Meghraj watershed were randomly selected and interviewed, representing $21 \%-24 \%$ of total village households. Similarly, a total of 300 households were interviewed from five villages in the Dharta watershed, representing 24\%-29\% of the total village households. Interviewees were either household heads or members who make decisions on behalf of household members.

Social and economic data were collected using a pre-tested questionnaire. Four major aspects were considered: (i) Household's livelihood assets_-human, natural, physical, financial and social assets [9]; (ii) household livelihood activities and strategies; (iii) household's perceptions of livelihood determinants, potential future changes, and adaptive intentions; and (iv) farming inputs and outputs. A pilot survey in both watersheds was carried out to finalize the questionnaire before full-scale surveys were conducted.

A separate survey was also conducted to answer research question about women's responsibilities regarding water and gendered perceptions of water use, availability and quality and who collects water. Five villages from Gujarat and Rajasthan were chosen and an average of 10 women, three men and three members of community associations were interviewed from each village. A random sampling method was used. Both surveys mentioned here were translated in Hindi and Gujarati and field investigators underwent a three-day training session conducted by the MARVI research team.

Cluster Analysis was used to identify relatively homogeneous groups of households/farmers based on selected groundwater use characteristics. Because the goal of this cluster analysis is to identify a typology of similar groups of groundwater users, the agglomerative hierarchical clustering method was used in this study. 


\subsection{Engagement with Schools and Local Communities}

Engagement of village communities through a range of activities that involved farmers, school communities and other members of village communities was an important part of the transdisciplinary approach used in this project. Field demonstrations on farmers' fields in the middle and end of the crop seasons were conducted on aspects, such as water requirements and water conservation practices, such as mulching and crop varieties that may be more drought tolerant or may result in improved income for a given water use. School children and teachers were engaged to record daily rainfall. Total weekly, monthly and seasonal values of rainfall were displayed on school noticeboards by students to create awareness about rainfall patterns and amounts and general awareness about water issues in their local areas.

Photovoice workshops were organized in villages and schools in both watersheds. Students and farmers were trained in photography and interestingly, most of them had never touched a camera in their lives. The idea of using a camera to express their ideas was something new and exciting for them and they actively participated in these workshops. They captured photographs regarding their past, present and future thoughts about water resources and groundwater as one of the critical factors of livelihood in village communities.

A newsletter in Hindi, called "MARVI Manthan"-a Hindi word Manthan meaning "deep contemplation"-was launched to share the project findings with village communities. This newsletter is published twice a year to coincide with the beginning of Rabi and Kharif seasons. The target audiences of this newsletter are farmers, the general community and other stakeholders, and the main purpose of the newsletter is to connect with local communities and pursue a dialogue with farmers for participatory use and management of local groundwater resources.

\section{Results}

\subsection{Understanding the Local Groundwater Situation}

The water table fluctuation for the Dharta and Meghraj watersheds, based on the monitoring of the Central Ground Water Board of India, are shown in Figures 5 and 6 respectively. The water table depth trends for the Dharta watershed indicate a depleting of groundwater from January 1994 to November 2000, after which the groundwater level seems to stabilize over the next 14 year period. From the twenty-year analysis, the net rate of groundwater depletion is of the order of $0.18 \mathrm{~m}$ per year. However, from the 2005 to 2013 period, the groundwater levels are increasing at the rate of $0.36 \mathrm{~m}$ per year. Over the 20-year period, the largest water table fluctuation, i.e., the maximum difference between the lowest and highest groundwater level, was estimated to be $24 \mathrm{~m}$. For the Meghraj watershed, the 18-year time series of groundwater levels show some large fluctuations in the water table but overall the net depletion in groundwater over 18 years seems to be negligible (Figure 6). The largest water table fluctuation for the Meghraj watershed was $8 \mathrm{~m}$ for the monitoring period considered. 
Figure 5. Central Ground Water Board groundwater head trends for the Dharta watershed from January 1994 to November 2013.

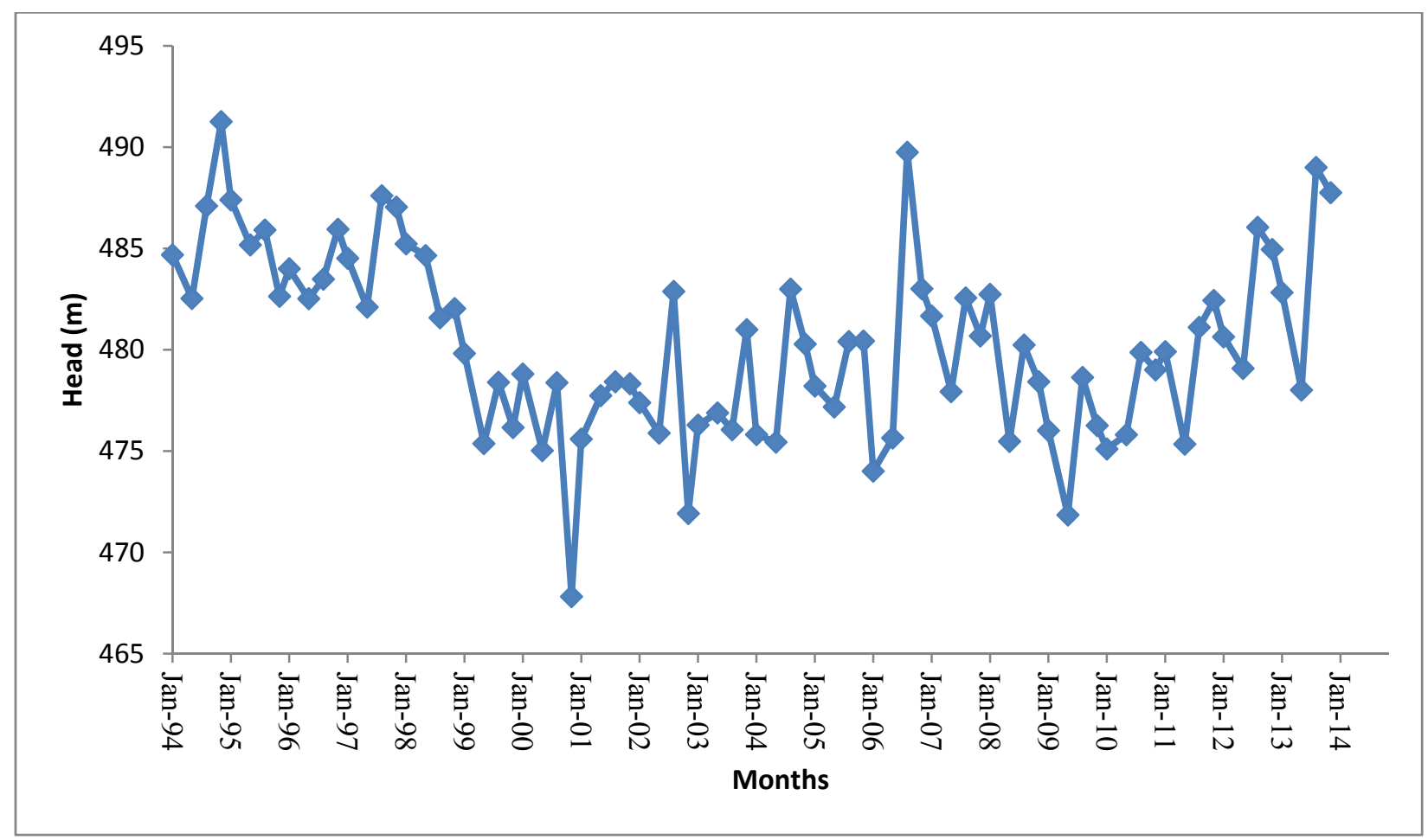

Figure 6. Central Ground Water Board groundwater head trends for the Meghraj watershed from January 2005 to November 2013.

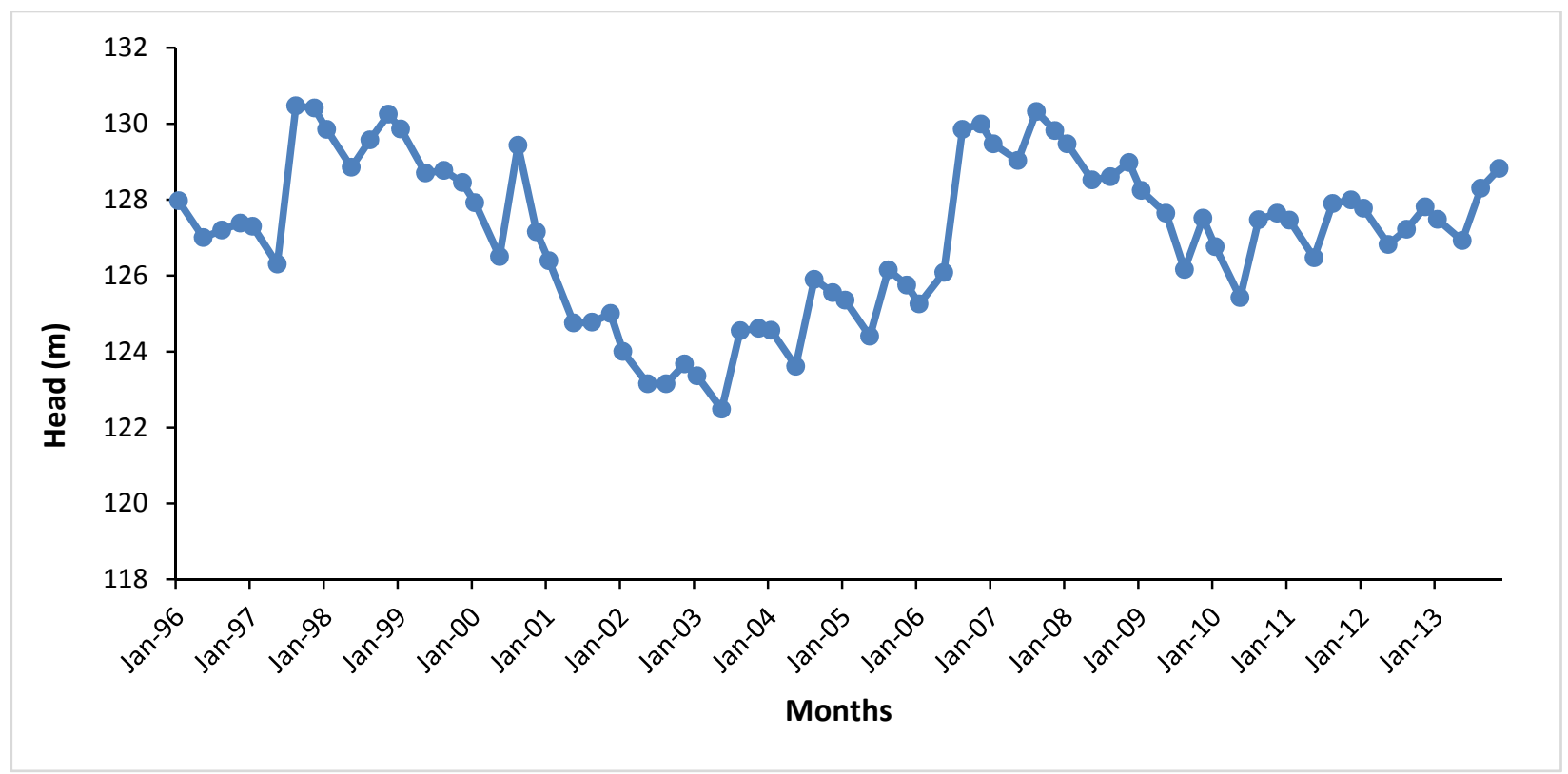

\subsection{Bhujal Jankaars}

While the BJs were monitoring the water table on a weekly basis, they have also helped to develop good linkages between this project and local communities, creating awareness about the groundwater issues in the two watersheds. The evaluation of the BJ approach so far indicated that BJs interact 
extensively with their communities as they do their measurement tasks on a weekly basis. They are sharing project outputs that are written in the local language and tailored to the needs of village communities, particularly sharing some observed water table data to indicate the state of groundwater fluctuations in the area.

Discussion with village communities indicates that BJs are now becoming an integral part of the engagement process and data collection activities in the project in both watersheds. There is now an increasing acceptance of BJs in village communities in regards to the source of information about the local rainfall, extent of water table fluctuations and groundwater quality. They have also become an important link between the project team and the village communities for mobilizing farmers for project meetings, field demonstrations and dissemination of research findings from the project.

\subsection{Engaging with Local Community}

The engagement activities with the farming community through water table monitoring, crop demonstration, work with local schools and targeted workshops have helped to create community awareness about the local groundwater situation and develop a suitable atmosphere for future meaningful dialogue with the community on local groundwater management issues and challenges. Competencies are being built to enhance the social capital of the area, with the aim of facilitating mutually beneficial collective action. The workshops with villagers have indicated that farming and village communities were all deeply concerned about groundwater quality and the rapidly declining groundwater supplies. The community is willing to explore options that will help in improved water availability for irrigation and drinking purposes but are currently more focused on water availability in their individual wells and not appreciating that groundwater needs to be managed at the village and watershed levels and beyond.

The school engagement activities in the project included a poster and painting competition on a range of topics such as drip irrigation, water harvesting, soil testing and climate change. It was observed that the engagement of school children in the project extended the groundwater dialogue with parents and may also result in longer-term benefits. Another important engagement activity was photovoice workshops that involved school communities and villagers and resulted in several hundred photos and the subsequent selection of over 50 photos with text from the participants. Photovoice is essentially a participatory process of collecting information and expressing issues and concerns through photographs, and it can be used to effectively engage different groups and communities in a research project. It can particularly help individuals and communities groups to record and reflect on their ideas and concerns, help them promote critical dialogue and exchange of knowledge about important issues at different levels and reach policymakers for improving situations. Photovoice in this study helped to significantly engage teachers, students and villagers and facilitated them to think about their current groundwater situation and some options they may like to pursue to improve the situation. In particular, through a participatory photography process, the activity helped to explore some basic questions regarding what water means to villagers in the two watersheds. The analysis of photographs and text provided by the participants indicated that women and youth tend to emphasize future and personal responsibility while older male participants focused more on current problems. Unsurprising, 
the photovoice data indicated that participants saw the lack of water as the overarching problem, alongside specific human behavior and infrastructure problems.

In general, engagement and awareness campaigns aimed at educating the beneficiaries on a potential policy may be more effective, rather than using uninformed preferences based on expert opinion to drive policy decisions for complex natural resources management issues and challenges [10] (Rogers, 2013). In this project, the engagement with the local community and stakeholders has been an important element of transdisciplinary research on complex issue such as groundwater sustainability and will particularly assist in an effective dialogue with village communities, government agencies, including policy makers at the state and national levels, for participatory management of groundwater.

\subsection{Socio-Economic Dimension of Groundwater Management}

A series of 11 questions in the livelihood survey elicited household attitudes and perceptions concerning the role of MAR, adequacy of groundwater to meet future needs, the influence of extraction of, and on, proximate wells, mechanisms to coordinate aquifer resources, who should pay or be compensated for aquifer remediation and willingness to adjust extraction for future needs.

In this study, it was assumed that the cluster analysis can be used to identify relatively homogeneous groups of households/farmers based on selected groundwater use characteristics. There are numerous ways in which clusters can be formed and the hierarchical clustering is one of the most straightforward methods to use. Hierarchical clustering can be either agglomerative or divisive. Agglomerative hierarchical clustering begins with every case being a cluster unto itself. At successive steps, similar clusters are merged. The algorithm ends with everybody in one huge, but useless, cluster. A divisive clustering starts with one large cluster with all objects in it and gradually broken into smaller sized clusters and ends up with clusters with one object (singleton cluster). Because the goal of this cluster analysis is to form similar groups of groundwater users, the agglomerative hierarchical clustering method is used in this study.

The cluster analysis of the factor scores in this study revealed a four-cluster solution (Table 1). Cluster composition and membership was predicted by eleven groundwater questions specified as $\mathrm{x}$-axis variables. The composition and relative values of the four groundwater management clusters mainly differentiated attitudes regarding the effectiveness of MAR, the willingness to reduce extraction for their children's future use, the role of markets in groundwater management and relative impacts of proximate wells. The four clusters were defined:

- Cluster A-future and market oriented, with a preference for MAR;

- Cluster B-future, non-market oriented with a focus on water use efficiency;

- Cluster C-present non-market orientation; and

- Cluster D-present market orientation.

The present, markets groundwater management (Cluster D) is characterized by a low likelihood of children taking over the farm in the future, does not believe that increasing the depth of the well will have an impact on neighbors, does not consider that MAR is the best way to maintain the well, does not deem that efficient water use is the best way to maintain the well but expects that a MAR scheme operated by a neighbor and self should be compensated. In contrast, the future, markets, MAR 
groundwater management (Cluster A) is typified by a high likelihood of children taking over the farm, the belief that increasing the depth of the well had an impact on neighbors, judge MAR as the best way to maintain groundwater resources, and believe that a neighbor's groundwater use reduced water in their own well.

Table 1. Response to different questions for different clusters.

\begin{tabular}{llccc}
\hline \multirow{2}{*}{ Groundwater Attitudinal Questions (Yes/No Response) } & \multicolumn{5}{c}{ Cluster (Proportion Yes Response) } \\
\cline { 2 - 5 } & GW A & GW B & GW C & GW D \\
\hline $\begin{array}{l}\text { How likely is it that your children will take over your farm in } \\
\text { the future? }\end{array}$ & 0.76 & 0.82 & 0.58 & 0.46 \\
\hline $\begin{array}{l}\text { Do you think that increasing the depth of your well has had } \\
\text { an impact on your neighbours? }\end{array}$ & 0.78 & 0.51 & 0.08 & 0.00 \\
\hline $\begin{array}{l}\text { Will the current depth of well/ tubewell be sufficient in the } \\
\text { next 5 years for your current cropping pattern? }\end{array}$ & 0.21 & 0.13 & 0.11 & 0.25 \\
\hline $\begin{array}{l}\text { Is MAR the best way to maintain your well? } \\
\text { Is efficient water use the best way to maintain your well? }\end{array}$ & 0.86 & 0.30 & 0.37 & 0.01 \\
\hline $\begin{array}{l}\text { Has your neighbour's groundwater use reduced the amount of } \\
\text { water in your well? }\end{array}$ & 0.89 & 0.93 & 0.04 & 0.15 \\
\hline $\begin{array}{l}\text { Would you be willing to share the water and costs of a } \\
\text { recharge scheme with other farmers close to you? }\end{array}$ & 0.96 & 0.73 & 0.32 & 0.86 \\
\hline $\begin{array}{l}\text { Would you be willing to reduce the number of watering if it } \\
\text { meant that water would be assured for your children? }\end{array}$ & 0.92 & 0.88 & 0.44 & 0.30 \\
\hline $\begin{array}{l}\text { If your managed recharge scheme increases the water } \\
\text { available for your neighbours, should they compensate you? }\end{array}$ & 0.99 & 0.08 & 0.05 & 0.93 \\
\hline $\begin{array}{l}\text { If your neighbours managed recharge scheme increases the } \\
\text { water in your well, should you pay them? }\end{array}$ & 0.99 & 0.11 & 0.07 & 0.96 \\
\hline $\begin{array}{l}\text { Would you be willing to adopt a new groundwater } \\
\text { management scheme that shared water and costs fairly } \\
\text { amongst all irrigators in your village? }\end{array}$ & 1.00 & 0.99 & 0.82 & 1.00 \\
\hline
\end{tabular}

The relative proportions of groundwater management cluster membership of respondents located in the two watersheds vary. About $9 \%$ of respondents from Gujarat are assigned membership in Cluster D, and $34 \%$ in Cluster A. The Rajasthan respondents are characterized by high proportional membership in Cluster D (55\%) and Cluster A (40\%). The farmers in Cluster D derive their groundwater information from traditional knowledge (42\%), family (20\%) and neighbors (19\%), while those in Clusters $\mathrm{A}$ and $\mathrm{B}$ acquire information from family, neighbors and television. However, the farmers in Cluster C only rely on traditional knowledge (26\%) and family $(22 \%)$. As to the level of trust, there is no significant difference among the four clusters.

The cluster analysis indicates that groundwater management perceptions and attitudes influence the willingness and capacity of well owners to adopt specific remediating technological solutions and their compliance with policy incentives. Differentiated perceptions and information sources revealed in the cluster membership and the distribution of clusters in the two watersheds suggests that a suite of targeted technologies and incentives, in contrast to a reliance on single technological solutions and policy instruments, is likely to achieve the highest adoption rates [11]. The analysis provides the basis 
for designing watershed specific policy instruments and technologies that align with statistically differentiated attitudes and perceptions revealed in the four clusters.

\subsection{Groundwater and Gender}

Though women are found to be significantly involved in irrigated agriculture in both the Dharta and Meghraj watersheds, the revenue generated from agriculture is entirely controlled by men. This clearly separated intra-household activities according to gender. These activities, however, are not separate from the water users' perspective, and this often impedes women's access to and control over this scarce resource. For instance, men usually have a greater say in water provision for irrigated agricultural production, which in turn influences agencies responsible for infrastructure and determines availability and security of water from the women's perspective. Even production from women's fields and household gardens is often controlled by men to a certain degree, as is the availability of water for non-agricultural tasks. This bias of water allocation and control is even greater in times of water scarcity.

Women were found to be responsible not only for domestic water use but also in the productive uses of water, such as vegetable growing and herding. The women interviewed are almost exclusively responsible for domestic chores and for maintaining hygiene in their households. Most of them commented that water scarcity has a direct impact on their access to water within the household as well as on the time they and their daughters and daughters-in-law have to spend in water collection. This means the time available for other activities in the household and livelihood opportunities becomes limited. In addition, mothers are concerned that their daughters are missing school because they have to help in water collection. A majority of them suggested boosting women representation in groundwater management.

The women interviewed are almost exclusively responsible for domestic chores and for maintaining hygiene in their households. Due to inadequate water being locally available for basic consumption in poorer households, women fetch water from nearby villages, where applicable, walking for more than $30 \mathrm{~min}$ and up to one hour per trip. The physical strain of collecting water is doubly compounded during the peak of summer, and women have to wait in long queues at water sources. This shows the precarious situation of women in households and also indicates how women are compelled to shoulder additional burdens for the welfare of their families.

Overall, the analysis of gender related issues of water indicate that for achieving broad livelihood improvement outcomes the needs of water from women's perspective cannot be ignored. Furthermore, the gender aspect of groundwater needs to be considered along with securing sustaining groundwater for crop production.

\section{Discussion}

\subsection{Capacity Building of BJs as Local Champions}

The training program of eight modules spread over about six months was aimed to orient the BJs regarding the MARVI project and to build their understanding about geology, hydrology, watershed management and mapping. While it was comparatively easy to develop an understanding of the depletion of surface water resources, the measures used for water harvesting and groundwater issues 
are quite complex to comprehend, both for the village communities as well as the project research partner field staff. However, in presenting these module inputs it was realized that, despite the difficulties, it was possible to demystify the technical aspects of groundwater management in a language that villagers could understand. It was also recognized that capacity building for the BJs has to be a gradual and continuous process, and one which blends theoretical inputs with practical exercises in their own villages in order to help them grasp these complex issues. Convincing people to work on an action research project that does not give them direct benefits requires a lot of effort. In addition, it was observed that groundwater management is a new concept that is not easily understood by rural communities. Retaining the BJs in the midst of other work opportunities available in and near the villages at a high remuneration was also an issue.

Besides well monitoring, the BJ's were also linked into other key project activities, viz.; village level meetings, field days during and after crop demonstrations and seed and fertilizer distribution. The BJs shared their experiences in a monthly meeting with project community organizers and prepared the plans and strategies for further activities. The BJs also interacted with other village members individually or through various village institutions like farmers' club, Sujal Samiti (water co-operative), Gramsabha (village council) and the like. In this way, the BJs were working as a communication bridge between the MARVI project team and villagers.

An interesting aspect of BJ involvement in this project was that the information collected by BJs made people in the villages curious about the MARVI project activities and triggered further communication. The location of monitoring wells also helped in spreading information as the wells were widely dispersed and every well owner asked why was the BJ taking readings and what will come out of it? These questions assisted in starting communication with the farmers about the current issues of groundwater scarcity. Some of the BJs became quite capable in preparing charts for displaying current rainfall and well water depth and hung these outside their house so that more people could see the results. Thus, as result of the BJ's involvement in the project most people in the villages came to know that this is a research project, not another project that focus on on-ground construction works, and that the research data which are being collected will be helpful for them in the future.

Given the skills that the BJs have acquired through their training, and subsequent practical experiences, they will be able to continue to contribute towards various development projects being implemented by local NGOs and the Government agencies, both in their own and the adjoining villages. It was observed that there was a dearth of competent human resources available at the village level before the commencement of this MARVI project, but now local villagers have relevant local groundwater knowledge, data collection experience and significant interest to improve their groundwater situation. It would be foolhardy for anybody not to utilize the local knowledge and skills on water and agriculture acquired by these BJs. At least one project partner is now collaborating with the Government of Gujarat to promote and effectively use the BJs to help implement the Mahatma Gandhi National Rural Employment Guarantee Act (MGNREGA), while in Rajasthan the BJs can continue to work with other government funded watershed development projects that are about to commence in the watershed. This is also in line with a recent report by the Planning Commission of India highlighting the need for building strong partnerships and collaborations among a broad spectrum of institutions and community to monitor and implement groundwater management strategies across India [12]. 


\subsection{Managing Complexity of Groundwater Use}

Farmers in the two watersheds face significant water shortages and the risk of crop failure even with a slightly abnormal decline or delay in monsoonal rains. Because of advances in drilling technology and its easy access, there has been a massive increase in the drilling of tubewells and deepening of open wells for irrigation. This has motivated farmers to extract groundwater from whatever depth it is available. As a consequence, this phenomenon has changed the idea of equity and sustainability of groundwater use in the two watersheds. Not only is the water table lowering or fluctuating considerably from year to year, which impacts on crop production but, also the quality of groundwater has deteriorated due to pumping from deeper aquifers. For example, in the Dharta watershed, there is some evidence that fluoride levels in groundwater (which is also used for drinking water supplies) for some villages are above the values recommended in the World Health Organization's guidelines [13]. In general, the groundwater situation in the two study watersheds also illustrates what is prevailing in many other parts of the States of Gujarat and Rajasthan and for that matter in many States of India.

Another complex and difficult issue is determining the limits of groundwater available for withdrawal, especially in hard rock aquifers with limited storage capacity. Without mechanisms and sanctions to coordinate individual withdrawals to meet socially agreed sustainable levels, groundwater use represents an open access resource where at the end everyone loses when the groundwater system gets over exploited. Access to and availability of groundwater affects household livelihoods and community well-being and, in some instances in India, it has been reported to have led to farmers taking the extreme step of ending their own lives [14]. Therefore, a proposal to coordinate groundwater use remains a source of conflict between competing farmer interests and is the subject of significant political argument. The flow of groundwater does not recognize boundaries of individual farms, villages or watersheds and the subtractive attribute implies that one farmer's gain through over-pumping incurs a loss of access for others. Therefore, in the current situation it is almost impossible to ensure equity of access among farmers and regulate its use sustainably.

While groundwater recharge of varying amounts occurs during each monsoon season, there has been a net lowering of water tables in many parts of Gujarat and Rajasthan [4]. The consequences are notably manifest during the Rabi season. In the absence of institutions, regulations to share the costs and risks of aquifer remediation, individual farmers are unlikely to undertake mitigating actions independently, as they are unlikely to be compensated for the benefits shared by the common pool community. The depth to the water table increases with pumping over a longer time period, and the impact of such pumping usually extends over larger areas. While groundwater recharge of varying amounts occurs during each monsoon season, the real impact of any lowering of the water table is severely felt during drought periods. Once groundwater has been extracted in excess of annual recharge, it is not easy for individual farmers to reverse this situation. It then requires co-operative actions from group of adjoining farmers to see any real impact of local recharge and demand management on the water table situation. 


\subsection{Challenges of Sharing Groundwater}

It is important to recognize that groundwater is an invisible, common property resource that is accessible to anyone who has a well and a pump, or can afford to dig a well and install a pump. The amount of groundwater available in hard rock aquifers with their limited storage capacity is not easy to predict, and hence it is hard to estimate the limit of groundwater pumping. Groundwater use is a good example of "tragedy of the commons" and "survival of the fittest" but at the end everyone loses when the groundwater system is over exploited. Groundwater can affect the livelihood and wellbeing of communities. Therefore, the regulation of groundwater use is a very sensitive issue for farmers and can become a significant political issue if not tackled properly

Common pool resources are characterized by costly exclusion of beneficiaries, a characteristic shared with public goods and rival consumption (or subtractable usage), a characteristic shared with private goods [15]. That is, the withdrawal of additional groundwater by an individual well owner appropriates and subtracts from the total available aquifer volume, reducing the opportunity of other irrigators to make use of the groundwater resource. When joint outcomes depend on multiple actors contributing inputs or actions that are costly and difficult to quantify and there is a lack of policy instruments to restrict usage, incentives exist for individuals to act opportunistically, often appropriating to a level where aggregate overuse occurs. A social dilemma occurs when individuals are tempted by short-term gains to over appropriate the common pool resource, thereby imposing group-shared costs on the common pool community. Additionally the opportunity exists for some individuals to free ride and benefit from the reductions in extraction or increases in recharge committed by other aquifer users. Individual over appropriation will eventually lead to falling water tables, increased pumping costs and lower crop productivity for all farmers.

The solution to the overexploitation of groundwater may well come from adequate licensing to access the resource. In India, the electricity for groundwater pumping is free in a number of states, and as such this has aggravated the problem of overuse groundwater. On the other hand, the State Government of Gujarat in recent years implemented a policy to limit groundwater pumping through limiting hours of electricity supply by constructing a separate power grid for farm sector. While the policy implementation in Gujarat has certainly limited the hours of pumping, this also pointed out that any attempt to deal with the issue of limiting user access to groundwater, in this case limiting the supply of electricity through a separate power grid, does involve some transaction cost of policy. An important outcome of the transdisciplinary research in this study would be to understand the issues and options of groundwater overexploitation from a number of perspectives and design a system of effective control for groundwater access.

\subsection{Making Community Engagement Effective}

Groundwater, being a common resource accessible by every member of the community individually, requires a common approach to its management. However, in general, past efforts of community involvement in aquifer management have been shown to be quite inefficient [4]. Therefore, for this study, it was decided to tackle this issue through more effective participation by the village communities involved, and thus community engagement was critically important to the success of the study. 
Effective participation is important groundwater management and in general it depends upon commitment rather than coercion and cannot be fully programmed or tightly controlled. Further, it involves resolving issues about the nature of participation in terms of extent and quality, as well as questions about who should participate. Sriskandarajah et al. [16] identified key themes in participative projects and included (i) the importance of the scope for genuine participation in decision-making if "community participation" is to be meaningful; (ii) the need to see participation as a continuing process of negotiation and decision-making rather than a once only input into project planning; (iii) the need for clear identification of interested parties as the first step in establishing community based resource management programs; and (iv) the need to recognize and build upon local knowledge and existing local resource management and institutional support practices.

A number of different forms of "Citizen participation" have been identified by Arnstein [17] in the form of a ladder, which moves from very tokenistic forms of participation (manipulation) and progresses to more meaningful forms of involvement (Citizen control), as illustrated in Figure 7. In the context of resource management projects, Sriskandarajah et al. [16] also suggested that at the three higher levels, community participation involved local people in making decisions about the management of the resources they used, while at the lower five levels, these decisions were made by bureaucratic "experts", with community members only being involved as either voluntary or paid labor. At the higher order, participation meant that communities either defined the ends themselves, or at least had a substantial input in defining them.

Figure 7. Degree of participation for managing groundwater (adapted from Arnstein, [17]).

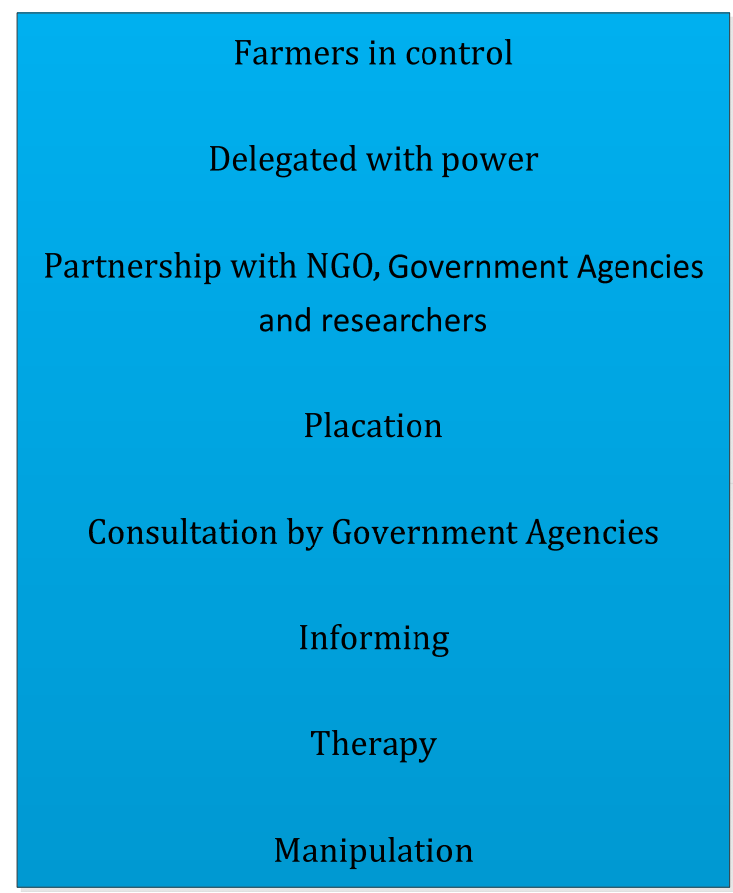

\section{Degree of power}

Degree tokenism

\section{Non-participation}

Pretty [18] suggested that two overlapping schools of thought and practice have evolved. One views participation as a means to increase efficiency, with the central notion that when people are involved, they are more likely to agree with and support the new development or service. The other view sees participation as a fundamental right, in which the main aim is to initiate mobilization for collective 
action, empowerment and institution building. In an analysis somewhat similar to that of Arnstein [17], Pretty [18] notes that participation has been used to justify the extension of and control by the state, as well as to build local capacity and self-reliance; it has been used to justify external decisions, as well as to devolve power and decision-making away from external agencies; and it has been used for data collection, as well as for interactive analysis.

In this study we felt the problems Shah [4] had identified were due to participation being at level A, while we would use community engagement to strive to achieve level (B), but also developing local capacity to move to level $\mathrm{C}$ (Table 2). It is considered that we have achieved level B participation and that this is continuing to strengthen as the project matures. As research results become available and are shared through the community engagement processes, notably via the BJs, it is hoped that the options for improvement to ensure groundwater sustainability will be taken up and lead to the emergence of level C participation.

Table 2. A selection of the typology of participation: How people participate in development programs and projects (adapted from Pretty [18]).

\begin{tabular}{|c|c|c|}
\hline $\begin{array}{c}\text { Participation } \\
\text { Level }\end{array}$ & $\begin{array}{c}\text { Participation } \\
\text { Type }\end{array}$ & Description \\
\hline A & $\begin{array}{c}\text { Functional } \\
\text { Participation }\end{array}$ & $\begin{array}{l}\text { Participation seen by external agencies as a means to achieve project goals, especially reduced } \\
\text { costs. People may participate by forming groups to meet predetermined objectives related to } \\
\text { the project. Such involvement may be interactive and involve shared } \\
\text { decision-making, but tends to arise only after major decisions have already been made by } \\
\text { external agents. At worst, local people may still only be co-opted to serve external goals. }\end{array}$ \\
\hline B & $\begin{array}{c}\text { Interactive } \\
\text { Participation }\end{array}$ & $\begin{array}{l}\text { People participate in joint analysis, development of action plans and formation or } \\
\text { strengthening of local institutions. Participation is seen as a right, not just the means to achieve } \\
\text { project goals. The process involves interdisciplinary methodologies that seek multiple } \\
\text { perspectives and make use of systemic and structured learning processes. As groups take } \\
\text { control over local decisions and determine how available resources are used, so they have a } \\
\text { stake in maintaining structures or practices. }\end{array}$ \\
\hline $\mathrm{C}$ & Self-Mobilization & $\begin{array}{l}\text { People participate by taking initiatives independently of external institutions to change } \\
\text { systems. They develop contacts with external institutions for resources and technical advice } \\
\text { they need, but retain control over how resources are used. Self-mobilization can spread if } \\
\text { governments and NGOs provide an enabling framework of support. Such self-initiated } \\
\text { mobilization may or may not challenge existing distributions of wealth and power. }\end{array}$ \\
\hline
\end{tabular}

\section{Concluding Remarks}

Sustainable groundwater use is a wicked problem and has technical, social, economic, policy and political dimensions. The access to groundwater for the farming communities is also an emotional issue as their livelihood and survival depends on it. Availability of relevant and reliable data related to the various aspects of groundwater and developing trust and support between local communities, NGOs and government agencies are the key to moving towards a dialogue to decide on what to do to achieve sustainable use of groundwater. Technical information on water table fluctuations, groundwater balance modeling, socio-economic and other data and analyses alone will hardly have any impact on over-exploitation of groundwater resources. This study has demonstrated that transdisciplinary 
research, which involves people who are going to benefit, is more effective in developing a deeper understanding of issues and exploring options to improve the current groundwater situation. In particular, the involvement of local villagers through groundwater monitoring, photovoice techniques and community workshops has been valuable in generating local knowledge and capacity building.

The socio-economic analysis revealed diverse attitudes to farmers' own and neighbors' groundwater responsibilities, mechanisms to coordinate groundwater use, attitudes to MAR, information sources and preferred groundwater and MAR managing agencies. Cluster membership variance highlights three key factors in designing participatory approaches and potential ground water management instruments in the two study sites. First, design principles need to address the diversity of attitudes and motivations observed in the sampled households, by emphasizing the participation of members across the whole cluster typology. Second, a reliance on a single instrument or approach to coordinate aquifer access is unlikely to align with the diverse attitudes observed across clusters, potentially resulting in low compliance rates or antagonizing sustainable groundwater management and MAR efforts. Third, while the transaction costs and resource demands make the tailoring of instruments to correspond with cluster attributes infeasible, community consultation is likely to reveal instrument sequencing as a viable strategy to promote aquifer sustainability. Addressing these three design principles in response to the observed household diversity is likely to enhance the prospects of community participation and improve aquifer recharge and groundwater pumping coordination.

The project has demonstrated that the harnessing of local experience and the indigenous knowledge of villagers has been useful in understanding the real issues of groundwater management, the geology of the area and groundwater use and changes over time. This engagement also helped in creating awareness about the project and sensitizing the community about the concept of groundwater management. The community is well aware that their groundwater is depleting at a fast rate but they were not aware of the technical reasons behind it. Local villagers had the perception that by digging deeper tubewells they would have more water, but they were not examining the issues related to groundwater recharge and water quality management. The regular monitoring of wells by BJs and the subsequent community meetings and the presence of project staff in the two study areas has now prompted the communities to talk among themselves about the future of their groundwater resources and the need to find options for managing and using groundwater more sustainably.

Efforts have been made by various government and NGO's for the augmentation of the water table, but this has not been enough to ensure long term sustainability. There is a need to awaken the people to take up groundwater recharge and rainwater harvesting and also manage demand and make irrigation more efficient. This is where the local administration must take responsibility and ensure that villagers are fully involved in such schemes. Planning is required at the micro level using participatory approaches to make each village self-sufficient in water.

\section{Acknowledgments}

Funding for this research was provided by the Australian Centre for International Agricultural Research, Canberra, Australia, and we appreciate the support of Evan Christen, Research Program Manager, Land and Water Resources during this study. Thanks to Joycelyn Applebee, Sita Ram Bhakar, Pradeep Bhatnagar and Anand Singh Jodha for their assistance during the study. 


\section{Author Contributions}

Data collection, analysis and writing: Basant Maheshwari, Ramesh Purohit, Hakimuddin, Tushaar Shah, Peter Dillon, Maria Estela Varua, John Ward, Roger Packham and Pennan Chinnasamy.

Mainly data collection and analysis: Yogita Dashora, Seema Dave, Prahlad Soni, Sachin Oza, Pradeep Singh, Sanmugam Prathapar, Ashish Patel, Yogesh Jadeja, Brijen Thaker, Rai Kookana, Harsharn Grewal, Kamal Yadav, Hemant Mittal, Michael Chew and Pratap Rao.

\section{Conflicts of Interest}

The authors declare no conflict of interest.

\section{References}

1. World Bank. Deep Well and Prudence: Towards Pragmatic Action for Addressing Groundwater Overexploitation in India; The World Bank: Washington, DC, USA, 2010; p. 97.

2. Siebert, S.; Burke, J.; Faures, J.M.; Frenken, K.; Hoogeveen, J.; Döll, P.; Portmann, F.T. Groundwater use for irrigation-A global inventory. Hydrol. Earth Syst. Sci. 2010, 14, 1863-1880.

3. Shah, T. India's groundwater irrigation economy: The Challenge of balancing livelihoods and environment. In Handbook on Environmental Economics in India; Chopra, K., Dayal, V., Eds.; Oxford University Press: New Delhi, India, 2008.

4. Shah, T. Taming the Anarchy: Groundwater Governance in South Asia; Routledge: New Delhi, India, 2009.

5. MNREGA (Mahatma Gandhi National Rural Employment Guarantee Act). Available online: http://www.nrega.ap.gov.in/ (accessed on 5 September 2014).

6. Uphoff, N.; Wijayaratna, C.M. Demonstrated Benefits from Social Capital: The Productivity of Farmer Organisations in Gal Oya, Sri Lanka. World Dev. 2000, 28, 1875-1890.

7. Central Ground Water Board (CGWB). Master Plan for Artificial Recharge to Ground Water in India; Government of India, Ministry of Water Resources: New Delhi, India, 2013. Available online: http://cgwb.gov.in/documents/MasterPlan-2013.pdf (accessed on 6 November 2014).

8. India-WRIS. Water Resources Information System of India. Available online: www.india-wris. nrsc.gov.in (accessed on 7 November 2014).

9. Chambers, R.; Conway, G.R. Sustainable Rural Livelihoods: Practical Concepts for the 21st Century; IDS Discussion Paper No. 296; Institute of Development Studies: Brighton, UK, 1991; p. 29.

10. Rogers, A.A. Public and expert preference divergence: Evidence from a choice experiment of marine reserves in Australia. Land Econ. 2013, 89, 346-370.

11. Ward, J.; Dillon, P. Design principles to coordinate managed aquifer recharge with natural resource management policies in Australia. Hydrogeol. J. 2012, 20, 943-956.

12. Planning Commission of India. Faster, Sustainable and More Inclusive Growth: An Approach Paper to 12th Five-Year Plan (2012-2017); Planning Commission, Government of India: New Delhi, India, 2011; p. 137.

13. Mishra, P. SWATCH, Udaipur, Rajasthan, India. Personal communication, 2014. 
14. Govardhan Das, S.V.; Rao, P.S.; Mani, K.A.S. Practices that can combat Poverty and Distress in India. In Proceedings of the 128th Session of International Conference on Agrarian Reform and Rural Development (ICARRD): New Challenges and Options for Revitalising Rural Communities, Porto Alegre, Rio Grande de Sul, Brazil, 7-10 March 2006; p. 12.

15. Ostrom, E. How types of goods and property rights jointly affect collective action. J. Theor. Polit. 2003, 15, 239-270.

16. Sriskandarajah, N.; Fisher, R.J.; Packham, R.G. Community Participation in Natural Resource Management: Lessons from Field Experience. In Proceedings of the Regional Seminar "Ecotone V" on Community Participation in Conservation, Sustainable Use and Rehabilitation of Mangroves in Southeast Asia, Ho Chi Minh City, Vietnam, 8-12 January 1996.

17. Arnstein, S.A. A Ladder of Citizen Participation. J. Am. Inst. Plan. 1969, 35, 216-224.

18. Pretty, J. Participatory Learning for Integrated Farming. In Internet Conference on Integrated Bio-Systems; Foo, E.-L., Senta, T.D., Eds.; Institute of Advanced Studies, UN University: Tokyo, Japan, 1998. Available online: http://www.ias.unu.edu/proceedings/icibs (accessed on 7 November 2014).

(C) 2014 by the authors; licensee MDPI, Basel, Switzerland. This article is an open access article distributed under the terms and conditions of the Creative Commons Attribution license (http://creativecommons.org/licenses/by/4.0/). 